\title{
Chức năng của miR-146b-5p trong Chondrocyte
}

\section{Potential function of miR-146b-5p in Chondrocyt}

\author{
Lê Huyền Ái Thúy ${ }^{1}$, Lê Thị Trúc Linh ${ }^{1 *}$ \\ ${ }^{1}$ Trường Đại học Mở Thành phố Hồ Chí Minh, Việt Nam \\ *Tác giả liên hệ, Email: linh.ltt@ou.edu.vn
}

THÔNG TIN

DOI: 10.46223/HCMCOUJS. tech.vi.16.1.1795.2021

Ngày nhận: 07/04/2021

Ngày nhận lại: 20/04/2021

Duyệt đăng: 25/05/2021

Tù khóa:

chức năng; chẩn đoán; microRNA tuần hoàn; miR146b-5p; thoái hoá khớp

Keywords:

circulating microRNA; diagnostic; miR-146b-5p; osteoarthritis

\section{TÓM TĂT}


abnormal expression of microRNA 146-5p could lead to osteoarthritis at least through the disorder of these signaling pathways.

\section{Giới thiệu}

MicroRNA là một nhóm RNA có kích thước từ 20 đến 25 nucleotide, có chức năng điều hòa biểu hiện gene bằng cách gắn đặc hiệu với một trình tự trên mRNA đích (Bartel, 2004). Sự biểu hiện bất thường của các miRNA trong bệnh THK đã được chứng minh trong nhiều nghiên cứu (Díaz-Prado et al., 2012; Le et al., 2016; Nakamura, Inloes, Katagiri, \& Kobayashi, 2011). MicroRNA tuần hoàn là các miRNA được phát hiện trong các dịch ngoại bào của cơ thể như máu ngoại vi (huyết tương, huyết thanh), dịch hoạt khớp, nước tiểu hoặc nước bọt. MicroRNA tuần hoàn có thể là sản phẩm phụ của tế bào hoặc là phân tử trung gian trong con đường truyền tín phản ảnh tình trạng bệnh lý của tế bào (Turchinovich, Samatov, Tonevitsky, \& Burwinkel, 2013). MicroRNA tuần hoàn là phân tử tiềm năng trong chẩn đoán bệnh và điều trị bệnh do phân tử này rất bền khi lưu thông trong máu, thời gian bán rã dài (khoảng 05 ngày trong huyết thanh) (Gantier et al., 2011), không bị phân hủy bởi Rnase, có thể duy trì ổn định ở nhiệt độ phòng và trong các điều kiện bất lợi của việc giải đông nhiều lần (Chen et al., 2008; Mitchell et al., 2008), đặc biệt là việc lấy mẫu không gây xâm lấn ở bệnh nhân. MicroRNA tuần hoàn đã được chứng minh là dấu chứng sinh học quan trọng cho nhiều bệnh như tiểu đường type II (Guay \& Regazzi, 2013), Parkinson, cao huyết áp, loãng xương, ung thư (Kumar, Vijayan, Bhatti, \& Reddy, 2017).

Rất nhiều nghiên cứu đã tìm thấy sự biểu hiện bất thường của miRNA tuần hoàn ở người bệnh THK so với người bình thường. Các miRNA biểu hiện quá mức trong huyết tương của bệnh nhân THK bao gồm miR-16, miR-20b, miR-19c, miR-30b, miR-93, miR-126, miR-184, miR-186, miR-195, miR-345 và miR-885-5p (Cuadra, González-Huerta, Romero-Cordoba, Hidalgo-Miranda, \& Miranda-Duarte, 2014), miR-146a, miRNA-19b-3p, miR-122-5p và miR486-5p. MicroRNA giảm biểu hiện ở huyết thanh bệnh nhân THK là miR-132, miR-33b-3p, miR-140-3p và miR-671-3p (Ntoumou et al., 2017), miRNA-19b-3p, miR-122-5p và miR-486$5 p$ tăng trong huyết thanh mẫu THK (Kong, Gao, Si, \& Zhao, 2017). Các nghiên cứu sau này tiếp tục tìm ra các miRNA khác có biểu hiện bất thường giữa người bệnh $\mathrm{THK}$ và người bình thường (Ali et al., 2020; Feng et al., 2020; Rousseau et al., 2020; Xie et al., 2019).

Tại Việt Nam, chúng tôi đã xác định miR-146b-5p tăng trong THK và là phân tử tiềm năng hỗ trợ trong chẩn đoán THK trong tương lai. Tuy nhiên, trước khi tiến hành xây dựng quy trình chẩn đoán sử dụng trong lâm sàn, việc xác định chức năng của miR-146b-5p trong tế bào khớp cung cấp thông tin làm nền tảng để khẳng định tiềm năng của miR-146b-5p như công cụ chẩn đoán bệnh.

Chức năng của miRNA được thực hiện thông qua sự tương tác giữa vị trí seed site trên miRNA và trình tự mục tiêu của nó trên vùng 3'UTR của mRNA. Có nhiều công cụ tin sinh học có thể dự đoán được các mRNA thông qua xác định sự tương tác này. Tuy nhiên, số liệu thu được từ sự tương tác này thường rất nhiều với nhiều trường hợp không chính xác khi kiểm chứng lại bằng thực nghiệm. Một trong những nguyên nhân là do một số mRNA chỉ được biểu hiện trong một loại tế bào cụ thể. Do vậy, trong nghiên cứu này chúng tôi thực hiện xác định chức năng của miRNA 146b-5p giới hạn trong tế bào khớp. Kết quả phân tích cho thấy miRNA-146b$5 p$ có thể tương tác với một số con đường truyền tín hiệu quan trọng. Từ đó, có thể thấy sự biến đổi bất thường của miR-146b-5p có thể là nguyên nhân dẫn tới những thay đổi bất thường trong tế bào khớp và từ đó dẫn tới bệnh. 


\section{Vật liệu và phương pháp}

\subsection{Các công cụ tin sinh học sử dụng để xác định vị trí di truyền của miR-146b-5p}

Vị trí của miRNA-146b-5p được xác định bằng cơ sở dữ liệu Gene của NCBI (n.d.), miRBase (n.d.).

\subsection{Dụ đoán các đích trục tiếp của miRNA-146b-5p}

Trình tự 3'UTR của các mRNA trong bộ gene được tải về từ cơ sở dữ liệu Ensembl Genome browser (n.d.). Các mRNA có vị trí gắn của mRNA 146b-5p được xác định bằng $\mathrm{R}-$ Studio.

\subsection{Dư đoán chức năng của miRNA-146b-5p}

Dự đoán chức năng của miRNA-146b-5p bằng David Bioinformatics Resources (n.d.) và Panther (n.d.).

\section{Kết quả nghiên cứu và thỏa luận}

\subsection{Kết quả}

\subsubsection{Vị trí di truyền của miR-146b-5p}

Thực hiện xác định vị trí của miR-146 trên bộ gene người bằng cơ sở dữ liệu Gene của NCBI. Vị trí của miR-146b trên bộ gene người thể hiện trong Hình 1.

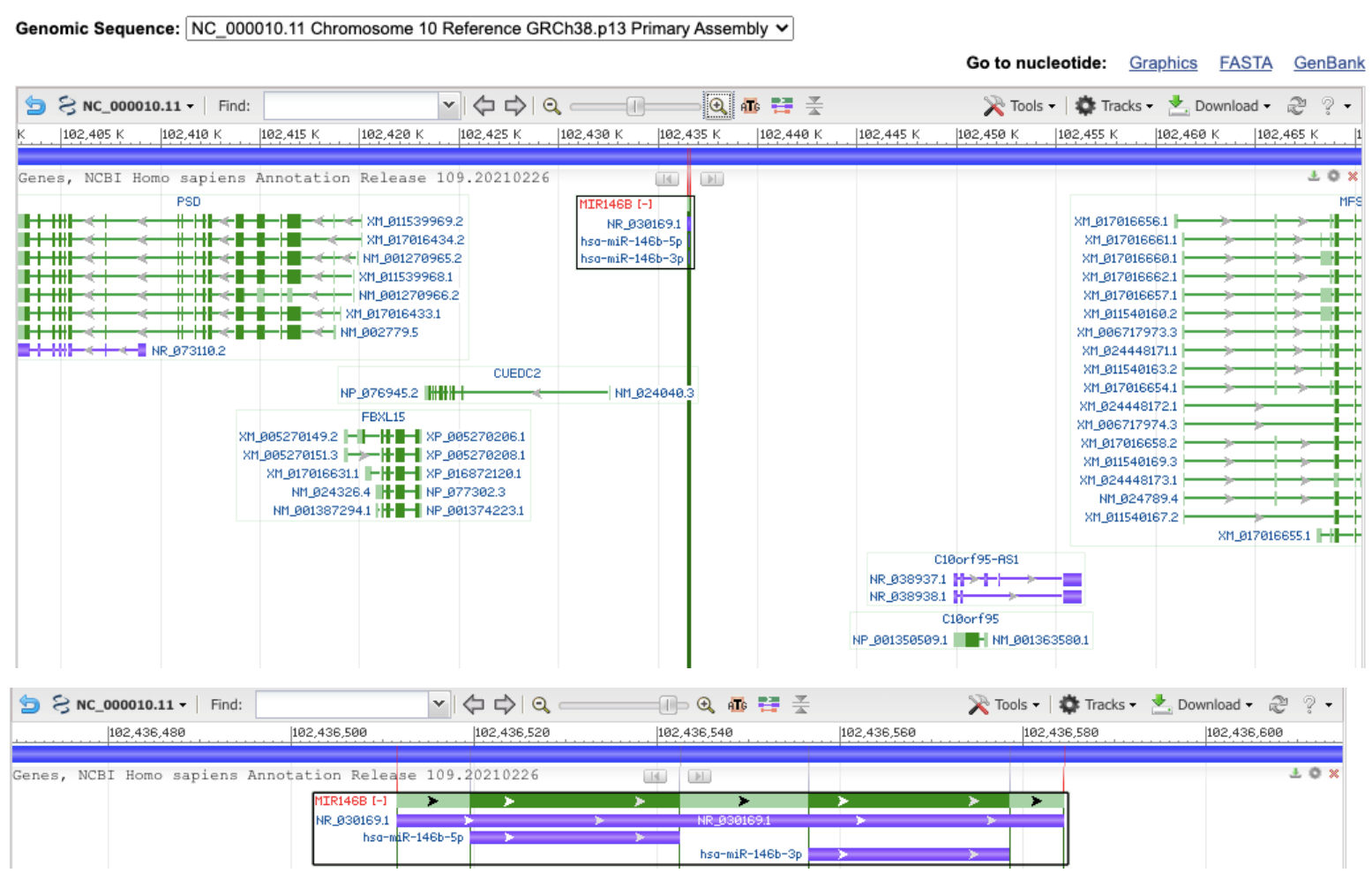

Hình 1. Vị trí của miR-146b-5p trên bộ gene người

MicroRNA 146 nằm trên NST số 10, mã số NR_030169.1 tại vị trí 102,436,512 đến $102,436,584$ có kích thước 73 nucleotide (Hình 1). MiR-146b không nằm trong vùng mã hoá của bất kỳ một gene này. Đây là một intergenic miRNA. Trình tự miR-146b-5p nằm từ vị trí $102,436,520$ đến $102,436,542$ có kích thước 23 nucleotide. Tương tự, miR-146b-3p nằm từ vị trí $102,436,557$ đến 102,436,578 có kích thước 22 nucleotide. 
Thực hiện xác định cấu trúc của tiền miRNA-146b và miR-146b-5p và $3 p$ bằng cơ sở dữ liệu miRbase (miRbase.org). Kết quả được thể hiện trong Hình 2.

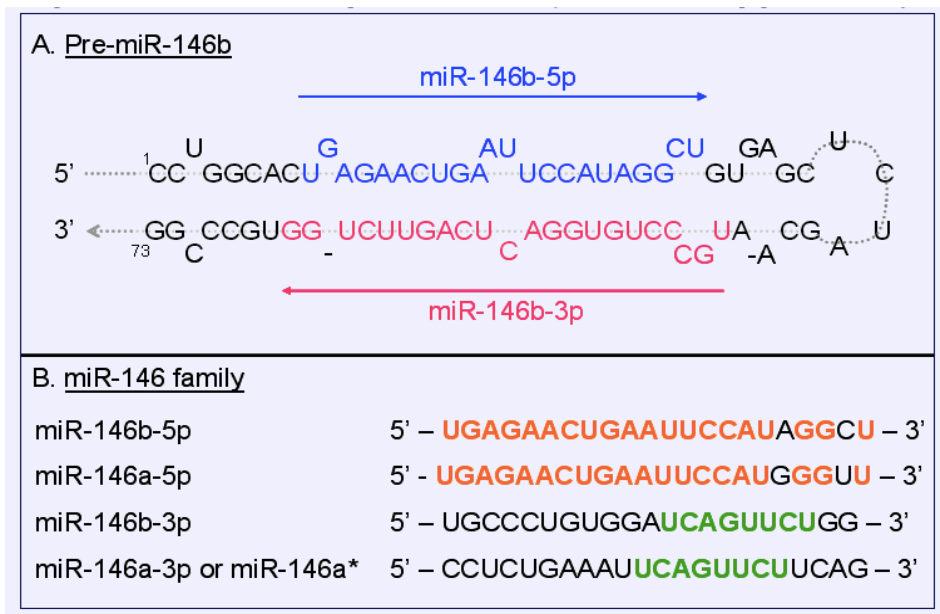

Hình 2. Cấu trúc và trình tự của MicroRNA 146b. (A) Cấu trúc kẹp tóc của tiền MicroRNA $146 \mathrm{~b}$ với trình tự miRNA trưởng thành của miR-146b-5p (màu xanh) và miR-146b-3p (màu đỏ). (B) Họ miR-146 gồm có miR-146b và -146a. Những nucleotide khác nhau được tô màu đen

Tiền miRNA $146 \mathrm{~b}$ có cấu trúc kẹp tóc dài 73 nucleotide với trình tự miRNA 146b-5p và $3 p$ trưởng thành nằm trên vùng thân của kẹp tóc của tiền miRNA-146b. MiRNA 146b thuộc họ với miR-146a. Về trình tự, miRNA-146a-5p và miRNA-146b-5p gần như tương đồng với nhau, chỉ khác 02 nucleotides. Ngược lại, miR-146a-3p và miR-146b-3p có trình tự khá khác nhau và chỉ tương đồng 08 nucleotides. Tuy nhiên, do những nucleotide khác nhau của họ miR-146 phần lớn thuộc vùng gắn của miRNA lên vùng 3 ' UTR (3' untranslation region) của mRNA, những thành viên của họ miR-146 không có chức năng tương đồng.

\subsubsection{Vị trí seed site của $m i R-146 b-5 p$}

MicroRNA thực hiện chức năng của chúng thông qua gắn trực tiếp lên trên vùng 3'UTR của mRNA bằng trình tự seed site của chính nó. Có 04 loại seed sites bao gồm $8 \mathrm{mer}, 7 \mathrm{mer}-\mathrm{A} 1$, 7 mer-m8 và 6 mer. Hiệu quả ức chế của miRNA lên phân tử mRNA có hiệu quả theo thứ tự giảm dần của 8 mer $>7$ mer-A1, 7mer-m8 $>6$ mer. Chúng ta thực hiện xác định các seed site của miR$146 \mathrm{~b}-5 \mathrm{p}$. Kết quả thể hiện như Hình 3.

\begin{tabular}{|c|c|c|c|}
\hline \multirow[t]{2}{*}{$\mathrm{mRN}^{\mathrm{m}}$} & 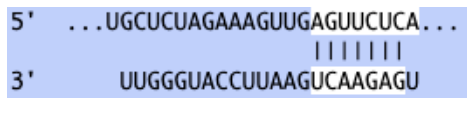 & $8 \mathrm{mer}$ & \multirow{2}{*}{ AGTTCTCA } \\
\hline & \multicolumn{2}{|l|}{ miRNA-146b-5p } & \\
\hline \multirow[t]{2}{*}{$\mathrm{mRN}^{\mathrm{mRN}}$} & $\begin{array}{c}5^{\prime}, \ldots \text { GCCUUUCCUUGCCCUGUUCUCAA... } \\
\text { IIIIII } \\
3^{\prime} \text { UCGgAUACCUUAAGUCAAGAGU }\end{array}$ & $\begin{array}{c}7 \mathrm{mer}- \\
\mathrm{A} 1\end{array}$ & \multirow{2}{*}{ GTTCTCA } \\
\hline & miRNA-146b-5p & & \\
\hline \multirow[t]{2}{*}{ mRN } & 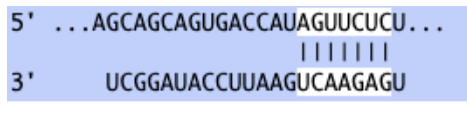 & $\begin{array}{c}7 \mathrm{mer}- \\
\mathrm{m8}\end{array}$ & \multirow{2}{*}{ AGTTCTC } \\
\hline & miRNA-146b-5p & & \\
\hline
\end{tabular}

Hình 3. Sự bắt cặp của miRNA-146b-5p với mRNA thông qua các seed sites.

MiRNA146b-5p gắn vào mRNA từ vị trí nucleotide 01-08 của miRNA. Các vị trí bắt cặp được thể hiện bằng các vạch thẳng 
Các vị trí seed sites của miR-146b-5p gồm có 8mer (AGTTCTCA), 7mer-A1 (GTTCTCA), 7mer -A8 (AGTTCTC), 6mer (GTTCTC).

\subsubsection{Dự đoán chức năng của miR-146b-5p trong tế bào khớp}

MicroRNA thuỷ phân mRNA. Do vậy, chức năng của miRNA phụ thuộc vào mức độ biểu hiện của mRNA trong một loại tế bào cụ thể. Chúng tôi đã có cơ sở dữ liệu về mức độ biểu hiện của các gene trong tế bào khớp (chondrocyte) thông qua giải trình tự thế hệ mới (next generation sequencing). Tiếp theo, tiến hành dự đoán chức năng của miR-146b-5p trong tế bào khớp thông qua kết hợp giữa phân tích xác định các vị trí seed site của miR-146b-5p trên mRNA với kết quả giải trình tự thế hệ mới các gene được biểu hiện trong tế bào khớp.

Kết quả phân tích (Phụ lục, Bảng 1) cho thấy có 328 gene là đích tiềm năng của miR$146 \mathrm{~b}-5 \mathrm{p}$ trong tế bào khớp. Những gene này có mức biểu hiện tốt (từ trung bình đến cao) và có vị trí gắn của miR-146b-5p trong vùng 3 'UTR.

Tiếp tục thực hiện phân tích chức năng của 328 gene tiềm năng ở trên bằng phần mềm David Bioinformatics Resources, một số chức năng quan trọng của miR-146b-5p trong các con đường truyền tín hiệu quan trọng trong tế bào khớp được tổng hợp trong Bảng 1 .

\section{Bảng 1}

Chức năng của các đích tiềm năng của miR-146b-5p

\begin{tabular}{|c|l|l|}
\hline STT & \multicolumn{1}{|c|}{ Genes } & \multicolumn{1}{c|}{ Tên gene } \\
\hline Wnt signalling pathway \\
\hline 1 & FZD1 & Frizzled-1 \\
\hline 2 & PPP2R5C & $\begin{array}{l}\text { Serine/threonine-protein phosphatase 2A 56 kDa regulatory subunit } \\
\text { gamma isoform }\end{array}$ \\
\hline 3 & FZD3 & Frizzled-3 \\
\hline 4 & BMPR1A & Bone morphogenetic protein receptor type-1A \\
\hline 5 & FZD9 & Frizzled-9 \\
\hline 6 & PRKCE & Protein kinase C epsilon type \\
\hline 7 & HDAC8 & Histone deacetylase 8 \\
\hline 8 & SIAH2 & E3 ubiquitin-protein ligase SIAH2 \\
\hline Notch signalling pathway \\
\hline 1 & LFNG & Beta-1,3-N-acetylglucosaminyltransferase lunatic fringe \\
\hline 2 & JAG1 & Protein jagged-1 \\
\hline 3 & NUMB & Protein numb homolog \\
\hline P38 MAPK signaling pathway \\
\hline Toll receptor signalling pathway \\
\hline 1 & TRAF6 & TNF receptor-associated factor 6 \\
\hline 2 & IRAK1 & Interleukin-1 receptor-associated kinase 1 \\
\hline \multicolumn{2}{|c|}{} \\
\hline \multicolumn{2}{|c|}{} \\
\hline
\end{tabular}




\begin{tabular}{|c|c|c|}
\hline STT & Genes & Tên gene \\
\hline 1 & RAC1 & Ras-related C3 botulinum toxin substrate 1 \\
\hline 2 & TRAF6 & TNF receptor-associated factor 6 \\
\hline \multicolumn{3}{|c|}{ Adhesion signalling } \\
\hline 1 & LPP & Lipoma-preferred partner \\
\hline 2 & $\mathrm{CCN} 4$ & $\mathrm{CCN}$ family member 4 \\
\hline 3 & TLN & Talin-2 \\
\hline 3 & NPTN & Neuroplastin \\
\hline \multicolumn{3}{|c|}{ Apoptosis pathway } \\
\hline 1 & CASP7 & Caspase-7 \\
\hline 2 & PRKCE & Protein kinase $\mathrm{C}$ epsilon type \\
\hline \multicolumn{3}{|c|}{ Cadherin signalling pathway } \\
\hline 1 & FZD1 & Frizzled-1 \\
\hline 2 & PTPN1 & Tyrosine-protein phosphatase non-receptor type 1 \\
\hline 3 & FZD3 & Frizzled-3 \\
\hline 4 & FZD9 & Frizzled-9 \\
\hline 5 & YES1 & Tyrosine-protein kinase Yes \\
\hline \multicolumn{3}{|c|}{ Intergin signalling } \\
\hline 1 & CRK & Adapter molecule crk \\
\hline 2 & FLNA & Filamin-A \\
\hline 3 & RAC1 & Ras-related C3 botulinum toxin substrate 1 \\
\hline \multicolumn{3}{|c|}{ Anti apoptosis pathway } \\
\hline 1 & PRAMEF1 & Family member 1(PRAMEF1) \\
\hline 2 & STIL & SCL/TAL1 interrupting locus \\
\hline 3 & SIN3A & SIN3 transcription regulator family member A \\
\hline 4 & SIX4 & SIX homeobox 4 \\
\hline 5 & TAF9B & TATA-box binding protein associated factor $9 \mathrm{~b}$ \\
\hline 6 & TRAF6 & TNF receptor associated factor 6 \\
\hline 7 & ANKLE2 & Ankyrin repeat and LEM domain containing 2 \\
\hline 8 & FLNA & Filamin A \\
\hline 9 & HIPK3 & Homeodomain interacting protein kinase 3 \\
\hline 10 & IFIT3 & Interferon induced protein with tetratricopeptide repeats 3 \\
\hline 11 & IRAK1 & Interleukin 1 receptor associated kinase 1 \\
\hline
\end{tabular}




\begin{tabular}{|c|l|l|}
\hline STT & \multicolumn{1}{|c|}{ Genes } & \multicolumn{1}{c|}{ Tên gene } \\
\hline 12 & ITCH & Itchy E3 ubiquitin protein ligase \\
\hline 13 & MED1 & Mediator complex subunit 1 \\
\hline 14 & PRKAA2 & Protein kinase AMP-activated catalytic subunit alpha 2 \\
\hline 15 & RARB & Retinoic acid receptor beta \\
\hline 16 & SIAH2 & Siah E3 ubiquitin protein ligase 2 \\
\hline 17 & USP47 & Ubiquitin specific peptidase 47 \\
\hline
\end{tabular}

Nguồn: Kết quả xử lý dữ liệu của nhóm tác giả

MicroRNA $146 b-5 p$ có thể tác động lên một số con đường truyền tín hiệu quan trọng trong tế bào khớp như Wnt signalling pathway (08 gene), Notch signalling pathway (03 gene), Toll like receptor sigalling pathway (02 gene), P38 MAPK signaling pathway (02 gene), Adhesion signalling (03 gene), Apoptosis pathway (02 gene), Cadherin signalling pathway (05 gene), Intergin signalling (03 gene), Anti apoptosis pathway (17 gene).

\subsection{Thảo luận}

MicroRNAs lưu thông trong máu là một phân tử quan trọng, có thể sử dụng làm chỉ thị phân tử giúp phát hiện nhiều bệnh ở người do đã được chứng minh có sự liên quan mật thiết đến tình trạng bệnh lý của bệnh nhân. Chúng tôi tìm thấy miR-146b-5p tăng trong huyết thanh của bệnh nhân THK ở Việt Nam.

MicroRNA146b đã được chứng minh tăng biểu hiện trong tế bào chondrocyte trong bệnh THK (Budd, De Andrés, Sanchez-Elsner, \& Oreffo, 2017). Tuy nhiên, tiềm năng sử dụng miRNA này như một công cụ hỗ trợ chẩn đoán vẫn chưa được xác định. Việc xác định chức năng của miR-146b-5p trong THK Việt Nam là một tiền đề để xây dựng phương pháp phát hiện sớm khi bệnh còn ở giai đoạn đầu, chưa có các biểu hiện lâm sàng. Tuy nhiên, hiện chức năng của miR-146b-5p trong tế bào khớp vẫn chưa được xác định. Trong nghiên cứu này, kết hợp giữa phương pháp dự đoán bằng công cụ tin sinh học và kết quả giải trình tự thế hệ mới về các mRNA biểu hiện trong tế bào khớp cho thấy, miRNA-146b-5p có thể tác động trực tiếp lên các con đường truyền tín hiệu quan trong của tế bào khớp như Wnt, Notch, Toll like receptor, P38 MAPK signaling pathway, Adhesion, Apoptosis, Cadherin, Intergin, Anti apoptosis signalling pathway. Sự bất hoạt của các con đường truyền tín hiệu này sẽ dấn đến các rối loại cho tế bào khớp và cuối cùng có thể dẫn đến THK.

Việc kết hợp giữa sử dụng kết quả giải trình tự và phân tích tin sinh học giúp dự đoán chức năng của miR-146b-5p chính xác cho tế bào khớp. Loại trừ được trường hợp các đích tiềm năng không có sự biểu hiện.

Ngoài chức năng miRNA-146b-5p trong tế bào khớp, chức năng của miR-146b-5p nói riêng và của miRNA tuần hoàn nói chung cần được xác định trong bức tranh tổng thể khi được vận chuyển trong các bóng màng để di chuyển trong máu và tới truyền thông tin cho các tế bào nhận. Việc xác định chức năng tổng thể này có thể được dự đoán thông qua sử dụng các công cụ tin sinh học xác định tất cả các mRNA trong tế bào có thể là đích tiềm năng của miRNA.

\section{Kết luận và gợi ý}

MicroRNA-146b-5p có thể tác động trực tiếp lên các con đường truyền tín hiệu quan trong của tế bào khớp như Wnt, Notch, Toll like, P38 MAPK signaling pathway, Adhesion, 
Apoptosis, Cadherin, Intergin, Anti apoptosis signalling pathway. Các kết quả đc tiên đoán bằng in silico này cần đc khẳng định bằng thực nghiệm trong thời gian tới.

\section{LỜI CẢM ƠN}

Nghiên cứu này được tài trợ bởi Bộ Giáo dục và Đào tạo của Việt Nam và Đại học Mở TP.HCM đối ứng cho đề tài của Bộ Giáo Dục và Đào tạo. Mã số: B2019-MBS-11.

\section{Tài liệu tham khảo}

Ali, S. A., Gandhi, R., Potla, P., Keshavarzi, S., Espin-Garcia, O., Shestopaloff, K., . . . Perruccio, A. (2020). Sequencing identifies a distinct signature of circulating microRNAs in early radiographic knee osteoarthritis. Osteoarthritis and Cartilage, 28(11), 1471-1481.

Bartel, D. P. (2004). MicroRNAs: Genomics, biogenesis, mechanism, and function. Cell, 116(2), 281-297.

Budd, E., De Andrés, M. C., Sanchez-Elsner, T., \& Oreffo, R. O. (2017). MiR-146b is downregulated during the chondrogenic differentiation of human bone marrow derived skeletal stem cells and up-regulated in osteoarthritis. Scientific Reports, 7(1), 1-11.

Chen, X., Ba, Y., Ma, L., Cai, X., Yin, Y., Wang, K., . . . Zhang, C. Y. (2008). Characterization of microRNAs in serum: A novel class of biomarkers for diagnosis of cancer and other diseases. Cell Research, 18(10), 997-1006. doi:10.1038/cr.2008.282

Cuadra, V. M. B., González-Huerta, N. C., Romero-Cordoba, S., Hidalgo-Miranda, A., \& Miranda-Duarte, A. (2014). Altered expression of circulating microRNA in plasma of patients with primary osteoarthritis and in silico analysis of their pathways. PloS One, 9(6), Article e97690.

David Bioinformatics Resources. (n.d.). Bioinformatics databse. Retrieved March 15, 2021, from https://david.ncifcrf.gov/home.jsp

Díaz-Prado, S., Cicione, C., Muiños-López, E., Hermida-Gómez, T., Oreiro, N., FernándezLópez, C., \& Blanco, F. J. (2012). Characterization of microRNA expression profiles in normal and osteoarthritic human chondrocytes. BMC Musculoskeletal Disorders, 13(1), 114.

Ensembl Genome browser. (n.d.). Retrieved March 10, 2021, from https://m.ensembl.org/index.html

Ensembl Mobile Site. (n.d.). Retrieved March 16, 2021, from https://m.ensembl.org/index.html

Feng, L., Feng, C., Wang, C. X., Xu, D. Y., Chen, J. J., Huang, J. F., . . . Shen, J. M. (2020). Circulating microRNA let $7 \mathrm{e}$ is decreased in knee osteoarthritis, accompanied by elevated apoptosis and reduced autophagy. International Journal of Molecular Medicine, 45(5), 1464-1476.

Gantier, M. P., McCoy, C. E., Rusinova, I., Saulep, D., Wang, D., Xu, D., . . Williams, B. R. (2011). Analysis of microRNA turnover in mammalian cells following Dicer1 ablation. Nucleic Acids Research, 39(13), 5692-5703. doi:10.1093/nar/gkr148

Guay, C., \& Regazzi, R. (2013). Circulating microRNAs as novel biomarkers for diabetes mellitus. Nature Reviews Endocrinology, 9(9), 513-521. doi:10.1038/nrendo.2013.86 
Kong, R., Gao, J., Si, Y., \& Zhao, D. (2017). Combination of circulating miR-19b-3p, miR-122$5 \mathrm{p}$ and miR-486-5p expressions correlates with risk and disease severity of knee osteoarthritis. American Journal of Translational Research, 9(6), 2852-2864.

Kumar, S., Vijayan, M., Bhatti, J. S., \& Reddy, P. H. (2017). MicroRNAs as peripheral biomarkers in aging and age-related diseases. Progress in Molecular Biology and Translational Science, 146, 47-94. doi:10.1016/bs.pmbts.2016.12.013

Le, L. T., Swingler, T. E., Crowe, N., Vincent, T. L., Barter, M. J., Donell, S. T., . . Clark, I. M. (2016). The microRNA-29 family in cartilage homeostasis and osteoarthritis. Journal of Molecular Medicine, 94(5), 583-596.

miRBase (n.d.). Retrieved March 18, 2021, from http://www.mirbase.org

Mitchell, P. S., Parkin, R. K., Kroh, E. M., Fritz, B. R., Wyman, S. K., Pogosova-Agadjanyan, E. L., . . . Tewari, M. (2008). Circulating microRNAs as stable blood-based markers for cancer detection. Proceeding of the National Academy of Sciences of the United States of America, 105(30), 10513-10518. doi:10.1073/pnas.0804549105

Nakamura, Y., Inloes, J. B., Katagiri, T., \& Kobayashi, T. (2011). Chondrocyte-specific microRNA-140 regulates endochondral bone development and targets Dnpep to modulate bone morphogenetic protein signaling. Molecular and Cellular Biology, 31(14), 30193028.

NCBI. (n.d.). Gene. Retrieved March 18, 2021, from https://www.ncbi.nlm.nih.gov/gene

Ntoumou, E., Tzetis, M., Braoudaki, M., Lambrou, G., Poulou, M., Malizos, K., . . Tsezou, A. (2017). Serum microRNA array analysis identifies miR-140-3p, miR-33b-3p and miR671-3p as potential osteoarthritis biomarkers involved in metabolic processes. Clinical Epigenetics, 9(1), 1-15.

Panther. (n.d.). Genes, genomes and orthologs. Retrieved March 18, 2021, from http://www.pantherdb.org/genes

Rousseau, J. C., Millet, M., Croset, M., Sornay-Rendu, E., Borel, O., \& Chapurlat, R. (2020). Association of circulating microRNAs with prevalent and incident knee osteoarthritis in women: the OFELY study. Arthritis Research \& Therapy, 22(1), 1-12.

Turchinovich, A., Samatov, T. R., Tonevitsky, A. G., \& Burwinkel, B. (2013). Circulating miRNAs: Cell-Cell communication function? Frontiers in Genetics, 4(119), 1-10. doi:10.3389/fgene.2013.00119

Xie, W., Su, W., Xia, H., Wang, Z., Su, C., \& Su, B. (2019). Synovial fluid microRNA-210 as a potential biomarker for early prediction of osteoarthritis. Bio Med Research International, 2019, 1-4. doi:10.1155/2019/7165406

\section{PHỤ LỤC}

\section{Bảng 1}

Các mRNA là đích tiềm năng của miR-146b-5p trong tế bào khớp

\begin{tabular}{|c|l|l|}
\hline STT & Gene name & \multicolumn{1}{c|}{ Gene names } \\
\hline 1 & $\underline{\text { TRAF6 }}$ & TNF receptor associated factor 6 \\
\hline 2 & $\underline{\text { IRAK1 }}$ & interleukin 1 receptor associated kinase 1 \\
\hline
\end{tabular}




\begin{tabular}{|c|c|c|}
\hline STT & Gene name & Gene names \\
\hline 3 & SEC23IP & SEC23 interacting protein \\
\hline 4 & $\underline{\mathrm{WWC} 2}$ & WW and $\mathrm{C} 2$ domain containing 2 \\
\hline 5 & PPP1R11 & protein phosphatase 1 regulatory inhibitor subunit 11 \\
\hline 6 & BCORL1 & BCL6 corepressor like 1 \\
\hline 7 & SORT1 & sortilin 1 \\
\hline 8 & ZNF649 & zinc finger protein 649 \\
\hline 9 & $\underline{\mathrm{USP} 32}$ & ubiquitin specific peptidase 32 \\
\hline 10 & $\underline{\text { NUMB }}$ & NUMB, endocytic adaptor protein \\
\hline 11 & $\underline{\text { PLSCR4 }}$ & phospholipid scramblase 4 \\
\hline 12 & $\underline{\text { SRSF6 }}$ & serine and arginine rich splicing factor 6 \\
\hline 13 & $\underline{\text { CARD10 }}$ & caspase recruitment domain family member 10 \\
\hline 14 & $\underline{\text { SIAH2 }}$ & siah E3 ubiquitin protein ligase 2 \\
\hline 15 & $\underline{\text { APPL1 }}$ & $\begin{array}{l}\text { adaptor protein, phosphotyrosine interacting with PH domain and } \\
\text { leucine zipper } 1\end{array}$ \\
\hline 16 & ZNF652 & zinc finger protein 652 \\
\hline 17 & $\underline{\text { SLC10A3 }}$ & solute carrier family 10 member 3 \\
\hline 18 & $\underline{\mathrm{MRS} 2}$ & magnesium transporter MRS2 \\
\hline 19 & $\underline{\underline{E I F} 4 \mathrm{G} 2}$ & eukaryotic translation initiation factor 4 gamma 2 \\
\hline 20 & C9orf72 & chromosome 9 open reading frame 72 \\
\hline 21 & $\underline{\text { ZNF354B }}$ & zinc finger protein $354 \mathrm{~B}$ \\
\hline 22 & $\underline{\mathrm{BRK} 1}$ & BRICK1, SCAR/WAVE actin nucleating complex subunit \\
\hline 23 & $\underline{\mathrm{DCAF} 12}$ & DDB1 and CUL4 associated factor 12 \\
\hline 24 & $\underline{\text { NEMP1 }}$ & nuclear envelope integral membrane protein 1 \\
\hline 25 & $\underline{\text { POFUT2 }}$ & protein O-fucosyltransferase 2 \\
\hline 26 & $\underline{\mathrm{FBXW} 2}$ & F-box and WD repeat domain containing 2 \\
\hline 27 & $\underline{\text { ZBTB2 }}$ & zinc finger and BTB domain containing 2 \\
\hline 28 & $\underline{\mathrm{ABL2}}$ & ABL proto-oncogene 2 , non-receptor tyrosine kinase \\
\hline 29 & HNRNPD & heterogeneous nuclear ribonucleoprotein D \\
\hline 30 & $\underline{\text { MMP16 }}$ & matrix metallopeptidase 16 \\
\hline 31 & $\underline{\text { RHOBTB3 }}$ & Rho related BTB domain containing 3 \\
\hline 32 & $\underline{\text { RARB }}$ & retinoic acid receptor beta \\
\hline 33 & $\underline{\mathrm{HIPK} 3}$ & homeodomain interacting protein kinase 3 \\
\hline
\end{tabular}




\begin{tabular}{|c|c|c|}
\hline STT & Gene name & Gene names \\
\hline 34 & SRP72 & signal recognition particle 72 \\
\hline 35 & $\underline{\text { SLC38A1 }}$ & solute carrier family 38 member 1 \\
\hline 36 & VASN & vasorin \\
\hline 37 & FBXO4 & F-box protein 4 \\
\hline 38 & TMEM19 & transmembrane protein 19 \\
\hline 39 & $\underline{\mathrm{LRCH} 1}$ & leucine rich repeats and calponin homology domain containing 1 \\
\hline 40 & $\underline{\text { ZNF506 }}$ & zinc finger protein 506 \\
\hline 41 & C3orf38 & chromosome 3 open reading frame 38 \\
\hline 42 & $\underline{\text { SLC12A6 }}$ & solute carrier family 12 member 6 \\
\hline 43 & $\underline{\text { YWHAB }}$ & $\begin{array}{l}\text { tyrosine } 3 \text {-monooxygenase/tryptophan 5-monooxygenase activation } \\
\text { protein beta }\end{array}$ \\
\hline 44 & $\underline{\text { ZNF90 }}$ & zinc finger protein 90 \\
\hline 45 & C8orf88 & chromosome 8 open reading frame 88 \\
\hline 46 & $\underline{\text { MED20 }}$ & mediator complex subunit 20 \\
\hline 47 & $\underline{\mathrm{CCK}}$ & cholecystokinin \\
\hline 48 & $\underline{\text { STRBP }}$ & spermatid perinuclear RNA binding protein \\
\hline 49 & $\underline{\text { YES1 }}$ & YES proto-oncogene 1, Src family tyrosine kinase \\
\hline 50 & $\underline{\text { TCF20 }}$ & transcription factor 20 \\
\hline 51 & $\underline{\text { PTPRA }}$ & protein tyrosine phosphatase, receptor type A \\
\hline 52 & $\underline{\text { GATAD1 }}$ & GATA zinc finger domain containing 1 \\
\hline 53 & $\underline{\text { THAP5 }}$ & THAP domain containing 5 \\
\hline 54 & $\underline{\text { VPS54 }}$ & VPS54, GARP complex subunit \\
\hline 55 & $\underline{\text { TMEM120B }}$ & transmembrane protein $120 \mathrm{~B}$ \\
\hline 56 & $\underline{\mathrm{AMPH}}$ & amphiphysin \\
\hline 57 & $\underline{Z}$ ZNF257 & zinc finger protein 257 \\
\hline 58 & $\underline{\mathrm{PPM} 1 \mathrm{~K}}$ & protein phosphatase, $\mathrm{Mg} 2+/ \mathrm{Mn} 2+$ dependent $1 \mathrm{~K}$ \\
\hline 59 & FLOT2 & flotillin 2 \\
\hline 60 & $\underline{\mathrm{RPF} 1}$ & ribosome production factor 1 homolog \\
\hline 61 & $\underline{\text { BIVM }}$ & basic, immunoglobulin-like variable motif containing \\
\hline 62 & $\underline{\text { SHCBP1 }}$ & SHC binding and spindle associated 1 \\
\hline 63 & $\underline{\mathrm{MOCS} 2}$ & molybdenum cofactor synthesis 2 \\
\hline 64 & ZFYVE1 & zinc finger FYVE-type containing 1 \\
\hline
\end{tabular}




\begin{tabular}{|c|l|l|}
\hline STT & Gene name & \\
\hline 65 & $\underline{\text { CASP7 }}$ & caspase 7 \\
\hline 66 & $\underline{\text { ZNF493 }}$ & zinc finger protein 493 \\
\hline 67 & $\underline{\text { ZNF367 }}$ & zinc finger protein 367 \\
\hline 68 & $\underline{\text { LANCL1 }}$ & LanC like 1 \\
\hline 69 & $\underline{\text { FLNA }}$ & filamin A \\
\hline 70 & $\underline{\text { MED1 }}$ & mediator complex subunit 1 \\
\hline 71 & $\underline{\text { BHLHE41 }}$ & basic helix-loop-helix family member e41 \\
\hline 72 & $\underline{\text { FZD1 }}$ & frizzled class receptor 1 \\
\hline 73 & $\underline{\text { TOR1A }}$ & torsin family 1 member A \\
\hline 74 & $\underline{\text { ZNF253 }}$ & zinc finger protein 253 \\
\hline 75 & $\underline{\text { MPHOSPH6 }}$ & M-phase phosphoprotein 6 \\
\hline 76 & $\underline{\text { ZNF662 }}$ & zinc finger protein 662 \\
\hline 77 & $\underline{\text { DTNA }}$ & dystrobrevin alpha \\
\hline 78 & $\underline{\text { HDAC8 }}$ & histone deacetylase 8 \\
\hline 79 & $\underline{\text { HHKB }}$ & phosphorylase kinase regulatory subunit beta \\
\hline 80 & $\underline{\text { TRMT6 }}$ & tRNA methyltransferase 6 \\
\hline 81 & $\underline{\text { ESYT2 }}$ & extended synaptotagmin 2 \\
\hline 82 & $\underline{\text { ZNF136 }}$ & zinc finger protein 136 \\
\hline 83 & $\underline{\text { CYP27B1 }}$ & cytochrome P450 family 27 subfamily B member 1 \\
\hline 84 & $\underline{\text { JAG1 }}$ & jagged 1 \\
\hline 85 & $\underline{\text { CDKN2AIP }}$ & CDKN2A interacting protein \\
\hline 86 & $\underline{\text { TMEM185B }}$ & transmembrane protein 185B \\
\hline 87 & $\underline{\text { SIX4 }}$ & SIX homeobox 4 \\
\hline 88 & $\underline{\text { AVL9 }}$ & AVL9 cell migration associated \\
\hline 89 & $\underline{\text { ROR1 }}$ & receptor tyrosine kinase like orphan receptor 1 \\
\hline 90 & $\underline{\text { CNIH4 }}$ & cornichon family AMPA receptor auxiliary protein 4 \\
\hline 91 & $\underline{\text { TSPYL1 }}$ & TSPY like 1 \\
\hline 92 & $\underline{\text { CCN4 }}$ & cellular communication network factor 4 \\
\hline 93 & $\underline{\text { INO80D }}$ & INO80 complex subunit D \\
\hline 94 & $\underline{\text { FAM210A }}$ & family with sequence similarity 210 member A \\
\hline 95 & - & \\
\hline 96 & $\underline{\text { NPTN }}$ & neuroplastin \\
\hline & & \\
\hline
\end{tabular}




\begin{tabular}{|c|c|c|}
\hline STT & Gene name & Gene names \\
\hline 97 & KLF7 & Kruppel like factor 7 \\
\hline 98 & CEP170B & centrosomal protein $170 \mathrm{~B}$ \\
\hline 99 & PAQR5 & progestin and adipoQ receptor family member 5 \\
\hline 100 & ZNF436 & zinc finger protein 436 \\
\hline 101 & $\underline{\text { SLC38A2 }}$ & solute carrier family 38 member 2 \\
\hline 102 & $\underline{\text { CXorf40A }}$ & chromosome $\mathrm{X}$ open reading frame $40 \mathrm{~A}$ \\
\hline 103 & $\underline{\text { GALNT10 }}$ & polypeptide $\mathrm{N}$-acetylgalactosaminyltransferase 10 \\
\hline 104 & C6orf 203 & chromosome 6 open reading frame 203 \\
\hline 105 & $\underline{\text { FAF2 }}$ & Fas associated factor family member 2 \\
\hline 106 & $\underline{\text { MOB1B }}$ & MOB kinase activator $1 \mathrm{~B}$ \\
\hline 107 & $\underline{\text { PTPN1 }}$ & protein tyrosine phosphatase, non-receptor type 1 \\
\hline 108 & CACNA2D1 & calcium voltage-gated channel auxiliary subunit alpha2delta 1 \\
\hline 109 & $\underline{\mathrm{LRRC}} 15$ & leucine rich repeat containing 15 \\
\hline 110 & $\underline{\mathrm{ITCH}}$ & itchy E3 ubiquitin protein ligase \\
\hline 111 & $\underline{\text { HMBOX1 }}$ & homeobox containing 1 \\
\hline 112 & $\underline{\text { ZDHHC13 }}$ & zinc finger DHHC-type containing 13 \\
\hline 113 & ZNF229 & zinc finger protein 229 \\
\hline 114 & $\underline{B Z W 1}$ & basic leucine zipper and W2 domains 1 \\
\hline 115 & $\underline{\text { INTS2 }}$ & integrator complex subunit 2 \\
\hline 116 & $\underline{\text { PUM1 }}$ & pumilio RNA binding family member 1 \\
\hline 117 & $\underline{\text { MTR }}$ & 5-methyltetrahydrofolate-homocysteine methyltransferase \\
\hline 118 & C7orf57 & chromosome 7 open reading frame 57 \\
\hline 119 & ELAVL1 & ELAV like RNA binding protein 1 \\
\hline 120 & B3GNT5 & UDP-GlcNAc:betaGal beta-1,3-N-acetylglucosaminyltransferase 5 \\
\hline 121 & $\underline{\text { POLR3A }}$ & RNA polymerase III subunit A \\
\hline 122 & $\underline{\text { KCNMA1 }}$ & potassium calcium-activated channel subfamily $\mathrm{M}$ alpha 1 \\
\hline 123 & $\underline{\mathrm{PRCP}}$ & prolylcarboxypeptidase \\
\hline 124 & $\underline{\text { TRIP12 }}$ & thyroid hormone receptor interactor 12 \\
\hline 125 & $\underline{\mathrm{LFNG}}$ & LFNG O-fucosylpeptide 3-beta-N-acetylglucosaminyltransferase \\
\hline 126 & $\underline{\text { NUP58 }}$ & nucleoporin 58 \\
\hline 127 & $\underline{\text { DCAF7 }}$ & DDB1 and CUL4 associated factor 7 \\
\hline 128 & ST7L & suppression of tumorigenicity 7 like \\
\hline
\end{tabular}




\begin{tabular}{|c|c|c|}
\hline STT & Gene name & Gene names \\
\hline 129 & SET & SET nuclear proto-oncogene \\
\hline 130 & $\underline{\mathrm{UMPS}}$ & uridine monophosphate synthetase \\
\hline 131 & GCFC2 & GC-rich sequence DNA-binding factor 2 \\
\hline 132 & GJC1 & gap junction protein gamma 1 \\
\hline 133 & $\underline{\text { SLC1A1 }}$ & solute carrier family 1 member 1 \\
\hline 134 & $\underline{\mathrm{ROBO} 1}$ & roundabout guidance receptor 1 \\
\hline 135 & $\underline{\mathrm{RAB} 8 \mathrm{~B}}$ & RAB8B, member RAS oncogene family \\
\hline 136 & $\underline{\text { IER5L }}$ & immediate early response 5 like \\
\hline 137 & ZNF365 & zinc finger protein 365 \\
\hline 138 & $\underline{\text { REEP5 }}$ & receptor accessory protein 5 \\
\hline 139 & CCDC6 & coiled-coil domain containing 6 \\
\hline 140 & ZNF737 & zinc finger protein 737 \\
\hline 141 & $\underline{\mathrm{PRKCE}}$ & protein kinase $\mathrm{C}$ epsilon \\
\hline 142 & FMNL3 & formin like 3 \\
\hline 143 & $\underline{\mathrm{KDM}} 2 \mathrm{~B}$ & lysine demethylase 2B \\
\hline 144 & $\underline{\mathrm{RBL1}}$ & RB transcriptional corepressor like 1 \\
\hline 145 & FBXO28 & F-box protein 28 \\
\hline 146 & $\underline{\text { ARL8A }}$ & ADP ribosylation factor like GTPase 8A \\
\hline 147 & $\underline{\text { NSD1 }}$ & nuclear receptor binding SET domain protein 1 \\
\hline 148 & $\underline{\text { RABGAP1 }}$ & RAB GTPase activating protein 1 \\
\hline 149 & $\underline{\text { ZDHHC7 }}$ & zinc finger DHHC-type containing 7 \\
\hline 150 & $\underline{\text { NFAT5 }}$ & nuclear factor of activated T cells 5 \\
\hline 151 & $\underline{\text { MINDY2 }}$ & MINDY lysine 48 deubiquitinase 2 \\
\hline 152 & $\underline{\underline{\text { IGSF1 }}}$ & immunoglobulin superfamily member 1 \\
\hline 153 & $\underline{\text { PHF20L1 }}$ & PHD finger protein 20 like 1 \\
\hline 154 & $\underline{\text { TET2 }}$ & tet methylcytosine dioxygenase 2 \\
\hline 155 & $\underline{\text { DCAF17 }}$ & DDB1 and CUL4 associated factor 17 \\
\hline 156 & ZNF605 & zinc finger protein 605 \\
\hline 157 & $\underline{\mathrm{FBXO} 3}$ & F-box protein 3 \\
\hline 158 & $\underline{\text { PDGFRA }}$ & platelet derived growth factor receptor alpha \\
\hline 159 & $\underline{\text { ARFGAP3 }}$ & ADP ribosylation factor GTPase activating protein 3 \\
\hline 160 & KRTAP1-5 & keratin associated protein $1-5$ \\
\hline
\end{tabular}




\begin{tabular}{|c|c|c|}
\hline STT & Gene name & Gene names \\
\hline 161 & $\underline{\text { SYT1 }}$ & synaptotagmin 1 \\
\hline 162 & SIPA1L1 & signal induced proliferation associated 1 like 1 \\
\hline 163 & $\underline{\text { MPPE1 }}$ & metallophosphoesterase 1 \\
\hline 164 & $\underline{\text { CIAO2A }}$ & cytosolic iron-sulfur assembly component $2 \mathrm{~A}$ \\
\hline 165 & $\underline{\text { ZNF398 }}$ & zinc finger protein 398 \\
\hline 166 & $\underline{\text { TLN2 }}$ & talin 2 \\
\hline 167 & $\underline{Z N F 195}$ & zinc finger protein 195 \\
\hline 168 & $\underline{\text { TRIM66 }}$ & tripartite motif containing 66 \\
\hline 169 & $\underline{\text { SAMD8 }}$ & sterile alpha motif domain containing 8 \\
\hline 170 & $\underline{\text { USP3 }}$ & ubiquitin specific peptidase 3 \\
\hline 171 & $\underline{\mathrm{BTG} 2}$ & BTG anti-proliferation factor 2 \\
\hline 172 & $\underline{\text { ZNF512B }}$ & zinc finger protein $512 \mathrm{~B}$ \\
\hline 173 & $\underline{\text { CALHM5 }}$ & calcium homeostasis modulator family member 5 \\
\hline 174 & $\underline{\text { DTWD2 }}$ & DTW domain containing 2 \\
\hline 175 & $\underline{\text { WDR47 }}$ & WD repeat domain 47 \\
\hline 176 & $\underline{\mathrm{ATP} 5 \mathrm{MC} 2}$ & ATP synthase membrane subunit c locus 2 \\
\hline 177 & $\underline{\mathrm{RNF} 26}$ & ring finger protein 26 \\
\hline 178 & $\underline{\text { ZNF138 }}$ & zinc finger protein 138 \\
\hline 179 & $\underline{\text { ITPRID2 }}$ & ITPR interacting domain containing 2 \\
\hline 180 & $\underline{\mathrm{USP} 47}$ & ubiquitin specific peptidase 47 \\
\hline 181 & $\underline{\text { TBC1D20 }}$ & TBC1 domain family member 20 \\
\hline 182 & $\underline{\text { ZNF486 }}$ & zinc finger protein 486 \\
\hline 183 & $\underline{\text { ZNF532 }}$ & zinc finger protein 532 \\
\hline 184 & $\underline{\text { CMTM6 }}$ & CKLF like MARVEL transmembrane domain containing 6 \\
\hline 185 & $\underline{\text { SRGAP2B }}$ & SLIT-ROBO Rho GTPase activating protein 2B \\
\hline 186 & $\underline{\mathrm{TMX} 1}$ & thioredoxin related transmembrane protein 1 \\
\hline 187 & $\underline{\text { TRMT1L }}$ & tRNA methyltransferase 1 like \\
\hline 188 & $\underline{\text { NUCKS1 }}$ & nuclear casein kinase and cyclin dependent kinase substrate 1 \\
\hline 189 & $\underline{\mathrm{ARMC} 8}$ & armadillo repeat containing 8 \\
\hline 190 & CEMIP & cell migration inducing hyaluronidase 1 \\
\hline 191 & $\underline{\text { ZNF841 }}$ & zinc finger protein 841 \\
\hline 192 & $\underline{\text { BCAP29 }}$ & B cell receptor associated protein 29 \\
\hline
\end{tabular}




\begin{tabular}{|c|c|c|}
\hline STT & Gene name & Gene names \\
\hline 193 & MCMBP & minichromosome maintenance complex binding protein \\
\hline 194 & CREBL2 & cAMP responsive element binding protein like 2 \\
\hline 195 & $\underline{\mathrm{HOOK} 3}$ & hook microtubule tethering protein 3 \\
\hline 196 & $\underline{\text { EMC1 }}$ & ER membrane protein complex subunit 1 \\
\hline 197 & ADAM19 & ADAM metallopeptidase domain 19 \\
\hline 198 & $\underline{\text { PTAR1 }}$ & protein prenyltransferase alpha subunit repeat containing 1 \\
\hline 199 & $\underline{\text { FBXL17 }}$ & F-box and leucine rich repeat protein 17 \\
\hline 200 & $\underline{\text { PEX19 }}$ & peroxisomal biogenesis factor 19 \\
\hline 201 & $\underline{\mathrm{RAC} 1}$ & Rac family small GTPase 1 \\
\hline 202 & $\underline{\text { NSL1 }}$ & NSL1, MIS12 kinetochore complex component \\
\hline 203 & $\underline{\text { CHML }}$ & CHM like, Rab escort protein 2 \\
\hline 204 & $\underline{\text { PSMD3 }}$ & proteasome $26 \mathrm{~S}$ subunit, non-ATPase 3 \\
\hline 205 & $\underline{\text { MRPS14 }}$ & mitochondrial ribosomal protein $\mathrm{S} 14$ \\
\hline 206 & ERLEC1 & endoplasmic reticulum lectin 1 \\
\hline 207 & $\underline{\text { MTAP }}$ & methylthioadenosine phosphorylase \\
\hline 208 & $\underline{B M P R 1 A}$ & bone morphogenetic protein receptor type $1 \mathrm{~A}$ \\
\hline 209 & $\underline{\text { SNX21 }}$ & sorting nexin family member 21 \\
\hline 210 & $\underline{\text { RACGAP1 }}$ & Rac GTPase activating protein 1 \\
\hline 211 & $\underline{\text { PMAIP1 }}$ & phorbol-12-myristate-13-acetate-induced protein 1 \\
\hline 212 & $\underline{\text { TRAK1 }}$ & trafficking kinesin protein 1 \\
\hline 213 & $\underline{\mathrm{TMX} 4}$ & thioredoxin related transmembrane protein 4 \\
\hline 214 & $\underline{\text { TNRC6A }}$ & trinucleotide repeat containing $6 \mathrm{~A}$ \\
\hline 215 & $\underline{\text { TFDP2 }}$ & transcription factor $\mathrm{Dp}-2$ \\
\hline 216 & $\underline{\mathrm{CDC} 37 \mathrm{~L} 1}$ & cell division cycle 37 like 1 \\
\hline 217 & $\underline{\text { ARFGEF3 }}$ & ARFGEF family member 3 \\
\hline 218 & $\underline{\mathrm{ALX} 4}$ & ALX homeobox 4 \\
\hline 219 & ZNF813 & zinc finger protein 813 \\
\hline 220 & $\underline{B L Z F 1}$ & basic leucine zipper nuclear factor 1 \\
\hline 221 & $\underline{\text { RAB31 }}$ & RAB31, member RAS oncogene family \\
\hline 222 & $\underline{\text { INPPL1 }}$ & inositol polyphosphate phosphatase like 1 \\
\hline 223 & $\underline{\mathrm{PRC} 1}$ & protein regulator of cytokinesis 1 \\
\hline 224 & RALGPS2 & Ral GEF with $\mathrm{PH}$ domain and $\mathrm{SH} 3$ binding motif 2 \\
\hline
\end{tabular}




\begin{tabular}{|c|c|c|}
\hline STT & Gene name & Gene names \\
\hline 225 & $\underline{\text { ZFAND5 }}$ & zinc finger AN1-type containing 5 \\
\hline 226 & $\underline{\text { PSMF1 }}$ & proteasome inhibitor subunit 1 \\
\hline 227 & LEPROT & leptin receptor overlapping transcript \\
\hline 228 & $\underline{\text { FZD3 }}$ & frizzled class receptor 3 \\
\hline 229 & $\underline{\text { ARPIN }}$ & actin related protein $2 / 3$ complex inhibitor \\
\hline 230 & ZBTB22 & zinc finger and BTB domain containing 22 \\
\hline 231 & $\underline{\text { PQLC3 }}$ & PQ loop repeat containing 3 \\
\hline 232 & $\underline{\mathrm{PHTF}} 2$ & putative homeodomain transcription factor 2 \\
\hline 233 & FAM120AOS & family with sequence similarity $120 \mathrm{~A}$ opposite strand \\
\hline 234 & ZFP3 & ZFP3 zinc finger protein \\
\hline 235 & $\underline{\text { IFIT3 }}$ & interferon induced protein with tetratricopeptide repeats 3 \\
\hline 236 & $\underline{\text { COPS8 }}$ & COP9 signalosome subunit 8 \\
\hline 237 & $\underline{\text { SIN3A }}$ & SIN3 transcription regulator family member A \\
\hline 238 & FNBP4 & formin binding protein 4 \\
\hline 239 & $\underline{\text { STIL }}$ & STIL, centriolar assembly protein \\
\hline 240 & $\underline{\underline{L P I N} 2}$ & lipin 2 \\
\hline 241 & $\underline{\text { TRIT1 }}$ & tRNA isopentenyltransferase 1 \\
\hline 242 & $\underline{\text { RPA3 }}$ & replication protein $\mathrm{A} 3$ \\
\hline 243 & $\underline{\text { PRKAA2 }}$ & protein kinase AMP-activated catalytic subunit alpha 2 \\
\hline 244 & $\underline{\mathrm{ARMH} 3}$ & armadillo-like helical domain containing 3 \\
\hline 245 & TRIM2 & tripartite motif containing 2 \\
\hline 246 & TBRG1 & transforming growth factor beta regulator 1 \\
\hline 247 & $\underline{\mathrm{TBC} 1 \mathrm{D} 2}$ & TBC1 domain family member 2 \\
\hline 248 & $\underline{\text { AUTS2 }}$ & AUTS2, activator of transcription and developmental regulator \\
\hline 249 & $\underline{\text { TAF9B }}$ & TATA-box binding protein associated factor $9 \mathrm{~b}$ \\
\hline 250 & $\underline{\text { IQGAP1 }}$ & IQ motif containing GTPase activating protein 1 \\
\hline 251 & $\underline{\mathrm{RFX} 7}$ & regulatory factor $\mathrm{X} 7$ \\
\hline 252 & $\underline{\text { PRAMEF1 }}$ & PRAME family member 1 \\
\hline 253 & $\underline{\text { ZNF626 }}$ & zinc finger protein 626 \\
\hline 254 & $\underline{\text { RAB29 }}$ & RAB29, member RAS oncogene family \\
\hline 255 & ZNF449 & zinc finger protein 449 \\
\hline 256 & $\underline{\mathrm{LCOR}}$ & ligand dependent nuclear receptor corepressor \\
\hline
\end{tabular}




\begin{tabular}{|c|c|c|}
\hline STT & Gene name & Gene names \\
\hline 257 & $\underline{\mathrm{PNPO}}$ & pyridoxamine 5'-phosphate oxidase \\
\hline 258 & $\underline{\text { PAICS }}$ & $\begin{array}{l}\text { phosphoribosylaminoimidazole carboxylase and } \\
\text { phosphoribosylaminoimidazolesuccinocarboxamide synthase }\end{array}$ \\
\hline 259 & $\underline{\text { RPL27A }}$ & ribosomal protein $\mathrm{L} 27 \mathrm{a}$ \\
\hline 260 & $\underline{\text { ARL17A }}$ & ADP ribosylation factor like GTPase 17A \\
\hline 261 & $\underline{\mathrm{HIPK} 1}$ & homeodomain interacting protein kinase 1 \\
\hline 262 & $\underline{\text { SPCS1 }}$ & signal peptidase complex subunit 1 \\
\hline 263 & $\underline{\text { DIS3L }}$ & DIS3 like exosome 3'-5' exoribonuclease \\
\hline 264 & $\underline{\mathrm{SLC} 2 \mathrm{~A} 3}$ & solute carrier family 2 member 3 \\
\hline 265 & $\underline{\text { GRID1 }}$ & glutamate ionotropic receptor delta type subunit 1 \\
\hline 266 & $\underline{\mathrm{C} 160 \mathrm{rf} 72}$ & chromosome 16 open reading frame 72 \\
\hline 267 & $\underline{\mathrm{RHOXF} 2}$ & Rhox homeobox family member 2 \\
\hline 268 & $\underline{\text { ZNF550 }}$ & zinc finger protein 550 \\
\hline 269 & $\underline{\text { MYO1B }}$ & myosin IB \\
\hline 270 & $\underline{\text { YAP1 }}$ & Yes associated protein 1 \\
\hline 271 & $\underline{\text { CAMTA1 }}$ & calmodulin binding transcription activator 1 \\
\hline 272 & $\underline{\text { PGM2L1 }}$ & phosphoglucomutase 2 like 1 \\
\hline 273 & $\underline{\mathrm{RHOXF} 2 \mathrm{~B}}$ & Rhox homeobox family member 2B \\
\hline 274 & ENDOD1 & endonuclease domain containing 1 \\
\hline 275 & $\underline{\text { PRMT3 }}$ & protein arginine methyltransferase 3 \\
\hline 276 & $\underline{\text { TRIM5 }}$ & tripartite motif containing 5 \\
\hline 277 & $\underline{\text { KIF13B }}$ & kinesin family member $13 \mathrm{~B}$ \\
\hline 278 & $\underline{\text { MYBL1 }}$ & MYB proto-oncogene like 1 \\
\hline 279 & $\underline{\text { FAM98B }}$ & family with sequence similarity 98 member B \\
\hline 280 & $\underline{\text { CUL4B }}$ & cullin 4B \\
\hline 281 & $\underline{\mathrm{GYG} 2}$ & glycogenin 2 \\
\hline 282 & APOL6 & apolipoprotein L6 \\
\hline 283 & $\underline{\mathrm{RNF} 4}$ & ring finger protein 4 \\
\hline 284 & $\underline{\text { KIF24 }}$ & kinesin family member 24 \\
\hline 285 & DCTN5 & dynactin subunit 5 \\
\hline 286 & $\underline{\mathrm{LPP}}$ & LIM domain containing preferred translocation partner in lipoma \\
\hline 287 & $\underline{\text { PRKAR2A }}$ & protein kinase cAMP-dependent type II regulatory subunit alpha \\
\hline
\end{tabular}




\begin{tabular}{|c|c|c|}
\hline STT & Gene name & Gene names \\
\hline 288 & TMEM237 & transmembrane protein 237 \\
\hline 289 & CNOT6 & CCR4-NOT transcription complex subunit 6 \\
\hline 290 & $\underline{\text { PTGFRN }}$ & prostaglandin $\mathrm{F} 2$ receptor inhibitor \\
\hline 291 & $\underline{\mathrm{CRK}}$ & CRK proto-oncogene, adaptor protein \\
\hline 292 & $\underline{\text { SUCLG2 }}$ & succinate-CoA ligase GDP-forming beta subunit \\
\hline 293 & $\underline{\text { TIMM17B }}$ & translocase of inner mitochondrial membrane 17B \\
\hline 294 & $\underline{\text { ADARB1 }}$ & adenosine deaminase, RNA specific B1 \\
\hline 295 & $\underline{\text { PKN2 }}$ & protein kinase N2 \\
\hline 296 & $\underline{\text { SPRTN }}$ & SprT-like N-terminal domain \\
\hline 297 & $\underline{\text { GOSR1 }}$ & golgi SNAP receptor complex member 1 \\
\hline 298 & ZNF441 & zinc finger protein 441 \\
\hline 299 & TMEM209 & transmembrane protein 209 \\
\hline 300 & $\underline{\mathrm{PPP} 2 \mathrm{R} 5 \mathrm{C}}$ & protein phosphatase 2 regulatory subunit B'gamma \\
\hline 301 & DAAM2 & dishevelled associated activator of morphogenesis 2 \\
\hline 302 & $\underline{\text { RUNDC3B }}$ & RUN domain containing 3B \\
\hline 303 & $\underline{\text { MR1 }}$ & major histocompatibility complex, class I-related \\
\hline 304 & $\underline{\text { CHST15 }}$ & carbohydrate sulfotransferase 15 \\
\hline 305 & $\underline{\text { MLLT1 }}$ & MLLT1, super elongation complex subunit \\
\hline 306 & $\underline{\text { EEPD1 }}$ & endonuclease/exonuclease/phosphatase family domain containing 1 \\
\hline 307 & $\underline{\mathrm{JAZF} 1}$ & $\mathrm{JAZF}$ zinc finger 1 \\
\hline 308 & $\underline{\text { ZNRF2 }}$ & zinc and ring finger 2 \\
\hline 309 & $\underline{\text { TRIM38 }}$ & tripartite motif containing 38 \\
\hline 310 & $\underline{\text { GART }}$ & $\begin{array}{l}\text { phosphoribosylglycinamide formyltransferase, } \\
\text { phosphoribosylglycinamide synthetase, } \\
\text { phosphoribosylaminoimidazole synthetase }\end{array}$ \\
\hline 311 & $\underline{\text { TMEM216 }}$ & transmembrane protein 216 \\
\hline 312 & $\underline{\text { ERICH1 }}$ & glutamate rich 1 \\
\hline 313 & $\underline{\text { PARP9 }}$ & poly(ADP-ribose) polymerase family member 9 \\
\hline 314 & $\underline{\text { ANKLE2 }}$ & ankyrin repeat and LEM domain containing 2 \\
\hline 315 & $\underline{\text { EHMT2 }}$ & euchromatic histone lysine methyltransferase 2 \\
\hline 316 & $\underline{\mathrm{SS} 18}$ & SS18, nBAF chromatin remodeling complex subunit \\
\hline 317 & ENTPD1 & ectonucleoside triphosphate diphosphohydrolase 1 \\
\hline
\end{tabular}




\begin{tabular}{|c|l|l|}
\hline STT & Gene name & \multicolumn{1}{c|}{ Gene names } \\
\hline 318 & $\underline{\text { SLC4A8 }}$ & solute carrier family 4 member 8 \\
\hline 319 & $\underline{\text { SH3YL1 }}$ & SH3 and SYLF domain containing 1 \\
\hline 320 & $\underline{\text { PSMC6 }}$ & proteasome 26S subunit, ATPase 6 \\
\hline 321 & $\underline{\text { CLN5 }}$ & CLN5, intracellular trafficking protein \\
\hline 322 & $\underline{\text { KCTD3 }}$ & potassium channel tetramerization domain containing 3 \\
\hline 323 & $\underline{\text { SHISAL1 }}$ & shisa like 1 \\
\hline 324 & $\underline{\text { DPY19L2 }}$ & dpy-19 like 2 \\
\hline 325 & $\underline{\text { SLC9A6 }}$ & solute carrier family 9 member A6 \\
\hline 326 & $\underline{\text { CUL5 }}$ & cullin 5 \\
\hline 327 & $\underline{\text { TOX }}$ & thymocyte selection associated high mobility group box \\
\hline 328 & $\underline{\text { FAM171A1 }}$ & family with sequence similarity 171 member A1 \\
\hline & & \\
\hline
\end{tabular}

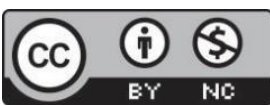

Creative Commons Attribution-NonCommercial 4.0 International License. 